\title{
Cost savings from averted prescription opioid- attributable dental diseases in the United States between 2013 and 2019
}

\author{
Daniel Erim ${ }^{1}$, Enihomo Obadan-Udoh ${ }^{2}$, Israel Agaku ${ }^{3}$
}

\author{
AFFILIATION \\ 1 University of North Carolina at Chapel Hill, Chapel Hill, United States \\ 2 University of California San Francisco School of Dentistry, San \\ Francisco, United States \\ 3 Harvard School of Dental Medicine, Boston, United States
}

CORRESPONDENCE TO

Daniel Erim. University of North Carolina at Chapel Hill, Chapel Hill,
North Carolina, United States. E-mail: erim.daniel@alumni.harvard.edu ORCID ID: https://orcid.org/0000-0002-6604-7640

KEYWORDS

opioids, dental disease, opioid prescription, cost savings

Received: 3 February 2021, Revised: 9 May 2021, Accepted: 9 May 2021

https://doi.org/10.18332/popmed/136488 patients with indicated dental diseases, and c) associated changes in direct and indirect costs of care.

RESULTS Estimated one-year risks of untreated caries and edentulism were $1.5 \%$ (95\% CI: $0.2-2.8, \mathrm{p}<0.05$ ) and $2.6 \%$ (95\% CI: 1.2-4.1, p<0.05) higher in NHANES participants with recent prescription opioid use compared to those without. About 102 million opioid prescriptions were withheld from about 91 million individuals between 2013 and 2019; this may have averted over 1.3 million cases of untreated caries and 2.3 million cases of edentulism, and may have saved up to $\$ 1.4$ billion in direct and indirect costs. CONCLUSIONS The decline in opioid prescriptions between 2013 and 2019 may have averted over 3.6 million combined cases of untreated caries and edentulism, and may have saved the US economy over $\$ 1.4$ billion.

\section{INTRODUCTION}

The US has been experiencing an opioid epidemic driven by prescription opioids ${ }^{1}$. With annual opioid prescriptions averaging over 200 million in the last decade, there are about 2 million substance use disorder diagnoses and 50000 overdose deaths each year ${ }^{1}$. The opioid epidemic cost the US over $\$ 1$ trillion between 2001 and 2007, and the annual cost to society ranges between $\$ 89$ billion and $\$ 117$ billion (2018 US\$) ${ }^{2}$. This economic burden results from criminal justice involvement (about 9\%), direct and indirect healthcare costs (up to $45 \%$ ), and workplace productivity loss (up to $46 \%)^{3}$. Between 2013 and 2019, the previously rising trend in annual opioid prescriptions underwent a reversal. With growing awareness of the opioid epidemic, increasing adoption of safer prescribing practices, and implementation of Prescription Drug Monitoring Programs, annual opioid prescriptions declined by about 7\% per year between 2013 and 2019,5. Expectedly, fewer opioid prescriptions should reduce the number of new opioid-attributable health conditions and associated costs 6 . Indeed, early reports indicate that in 2018, overdose deaths decreased for the first time in almost three decades ${ }^{7}$. However, little is known about other opioid-related health conditions that may have been averted by the decline in opioids prescriptions. In the oral health landscape, this knowledge gap is compounded by unclear associations between prescription opioid use and common dental diseases (i.e. periodontitis, untreated caries and edentulism $)^{8,9}$. To fill these gaps, this study's goals were: a) to evaluate associations between prescription opioid use and common dental diseases, and b) to estimate averted new cases of common dental diseases (and associated cost savings) from the indicated decline in opioid prescriptions. 
This study's findings are expected to contribute to the national discourse on impacts of the opioid epidemic.

\section{METHODS}

\section{Data sources}

National Health and Nutrition Examination Survey (NHANES) NHANES is a nationally representative survey of the noninstitutionalized US civilian population to assess the health and nutritional status of adults and children in the United States ${ }^{10}$. The survey combines interviews with physical examinations, and oral health outcomes are usually assessed by calibrated examiners to minimize measurement error in self-reported outcomes ${ }^{11}$. Other characteristics of NHANES have been previously described ${ }^{10}$. For adequate statistical power, we created two pooled datasets across three NHANES cycles: 2009-2010, 2011-2012, and 2013-2014 cycles to study periodontitis among persons aged $\geq 30$ years; and 2011-2012, 2013-2014, and 2015-2016 cycles to study untreated caries and edentulism among individuals aged $\geq 20$ years.

\section{Opioid Prescriptions in the US}

Data on the total number of opioid prescriptions dispensed in the United States between 2012-2019 were obtained from the Centers for Disease Control and Prevention and are presented in Table $1^{12}$. We estimated the decline in opioid prescriptions as year-on-year differences between 2013 and 2019.

\section{Measures}

Oral health outcomes

Oral health measurements in the NHANES datasets include

Table 1. Total number of opioid prescriptions dispensed in the United States 2012-2019

\begin{tabular}{|c|c|c|}
\hline & $\begin{array}{c}\text { Annual opioid } \\
\text { prescriptions } \\
\text { (observed) }\end{array}$ & $\begin{array}{c}\text { Reductions in } \\
\text { annual opioid } \\
\text { prescriptions }^{\dagger}\end{array}$ \\
\hline 2012 & 255207954 & NA \\
2013 & 247090443 & 8117511 \\
2014 & 240993021 & 6097422 \\
2015 & 226819924 & 14173097 \\
2016 & 214881622 & 11938302 \\
2017 & 191909384 & 22972238 \\
2018 & 168158611 & 23750773 \\
2019 & 153260450 & 14898161 \\
Total & 1443113455 & 101947504 \\
\hline
\end{tabular}

NA: not applicable. Previous years' prescriptions are as follows: 215917663 (2006); 228543773 (2007); 237860213 (2008); 243738090 (2008); 251088904 (2010); and 252167963 (2011). Note the rising opioid prescriptions before 2012. $f$ The data were obtained from the Centers for Disease Control and Prevention (U.S. Opioid Dispensing Rate Maps). † Reductions were calculated as year-on-year differences in annual opioid prescriptions. probing depth, gingival recession, attachment loss, and indices of periodontal disease (mild, moderate, severe, or any periodontitis). We used available oral health measures to create binary indicators of periodontitis (present or absent based on CDC/American Academy of Periodontology case definitions), untreated caries ( $\geq 1$ tooth affected vs none) and edentulism ( $\geq 1$ tooth missing vs none) ${ }^{13}$.

\section{Indicator of prescription opioid use}

Recent (i.e. in the past 30 days) use of hydrocodone, oxycodone, propoxyphene, codeine, tramadol, opium, morphine, fentanyl, hydromorphone, meperidine, pentazocine, oxymorphone, or tapentadol was also assessed in the indicated NHANES cycles; these data were used to create a binary indicator of recent prescription opioid use.

\section{Others}

Control covariates of interest (based on plausible associations with the key independent and/or outcome variables) in the NHANES datasets were gender, age, race/ethnicity, educational level, poverty level, health insurance status, country of birth, veteran status, depressive symptoms, cigarette smoking, alcohol use, marijuana use, methamphetamine use, cocaine use, heroin use, comorbidities (including arthritis, diabetes, thyroid disorders, hypertension, hypercholesterolemia, angina, coronary arterial disease, heart attack, stroke, asthma, bronchitis, emphysema, liver diseases and cancer) and NHANES cycle.

\section{Analyses}

Evaluating associations between prescription opioid use and common dental diseases

Logistic regression was used to evaluate each indicator of common dental diseases as a function of recent prescription opioid use and control covariates specified above. An alpha of 0.05 was used to determine statistical significance. The logistic regression models were also used to predict the six-year (i.e. 2009-2014 and 2011-2016) risk differences of indicated dental diseases across respondents with and without recent prescription opioid use (i.e. as differences in respective six-year cumulative incidences). These sixyear risk differences were then converted to one-year risk differences using methods described by Fleurence et al. ${ }^{14}$.

\section{Averted cases of common dental diseases and associated cost- savings}

First, we estimated the number of individuals that would have received the averted opioid prescriptions by assuming that $29 \%$ of adults with an opioid prescription have refills within the same year (about 1.6 refills per patient) ${ }^{15}$. We then estimated the number of common dental disease cases affected by the decline in opioid prescriptions as the product of respective one-year risk differences and number of individuals that would have received opioid prescriptions 
otherwise.

Associated cost savings were measured in two dimensions: productivity loss and direct costs of initial treatment. Productivity loss was assessed using an approach suggested by the World Health Organization's Commission on Macroeconomics and Health ${ }^{16}$. This approach values one disability-adjusted life year (DALY) at one year of per capita gross domestic product (GDP) to approximate productivity loss ${ }^{17}$. Using this information, we estimated the per capita productivity loss for each indicated dental disease by dividing the product of 2016 per capita GDP and respective 2016 DALYs for individuals aged $\geq 15$ years by the respective number of cases in the $U^{17-20}$. For example, per capita productivity loss for untreated caries was calculated by dividing the product of 2016 US per capita GDP (\$58000, World Bank) and total disability adjusted life years for untreated caries in 2016 (73711) by the total number of untreated caries cases in the US for those aged $\geq 15$ years ${ }^{18}$. The number of untreated caries cases in the US was estimated by summing products of prevalence of untreated caries $(20 \%, 26 \%$ and $18 \%$ in individuals aged 15-19 years, $20-64$ years, and $\geq 65$ years, respectively) by the number of individuals in indicated age groups (from the U.S. Census bureau $)^{21-24}$. Similarly, per capita productivity loss for edentulism was calculated by dividing the product of 2016 US per capita GDP and total disability adjusted life years for edentulism in 2016 (662274) by the number of edentulous adults in the US (178 million $)^{18,25}$. Averted productivity loss was calculated as the product of per capita productivity loss and averted cases of indicated dental diseases.

Probabilities and direct costs of initial treatment of periodontitis, caries and edentulism were obtained from various sources. Direct costs of initial treatment for periodontitis were obtained from a study by Albert et al. ${ }^{26}$, while direct costs of initial treatment for dental caries were obtained from a study by 0 'Connell et al. ${ }^{27}$. Per capita direct treatment costs for untreated caries account for the probability of initiating treatment in the index year (0.86), as well as the distribution and average costs of common treatment types (i.e. resin 1 [ $40 \%$ at $\$ 175$ per case], resin $2+$ [39\% at $\$ 210$ per case], amalgam 1 [ $8 \%$ at $\$ 129$ per case], amalgam $2+[8 \%$ at $\$ 152$ per case], tooth extraction [5\% at $\$ 175$ per case $]$ and crown $[<1 \%$ at $\$ 1075$ per case $]]^{20,28}$. Similarly, per capita direct treatment costs for edentulism account for the probability of initiating treatment in the index year (0.29), as well as the distribution and lowest cost of various treatment types (i.e. single dentures [90\% at $\geq \$ 600$ per case for basic to mid-range], implants [ $5 \%$ assumed at $\geq \$ 3000$ per case], and dental bridges [ $5 \%$ assumed at $\geq \$ 1500$ per case]) from a targeted review of different data sources ${ }^{29-42}$. Alternative distributions of use of dental implants and bridges for initial treatment of edentulism were examined in sensitivity analyses. All costs were adjusted to 2020 values using appropriate indices from the United States Bureau of Labor Statistics.

\section{RESULTS}

\section{Associations between prescription opioid use and common dental diseases}

Estimated measures of association between prescription opioid use and periodontitis, edentulism and untreated caries are presented in Table 2. Estimated one-year risks of untreated caries and edentulism were 1.5\% (95\% CI: $0.2-$ $2.8, \mathrm{p}<0.05$ ) and 2.6\% (95\% CI: 1.2-4.1, p<0.05) higher in NHANES participants with recent prescription opioid use compared to those without recent prescription opioid use. We found no association between recent prescription opioid use and periodontitis and thus excluded periodontitis from further analyses.

\section{Averted cases of common dental diseases and associated cost-savings}

An estimated 102 million opioid prescriptions were witheld from about 91 million individuals between 2013 and 2019, as presented in Table 3. This reduction in opioid prescriptions over the study period may have prevented over 1.3 million cases of untreated caries. With estimated per capita productivity loss and direct treatment costs of $\$ 77$ and $\$ 151$, respectively, averted cases of untreated caries resulted in $\$ 312$ million in cost-savings (i.e. about $\$ 105$ million in productivity loss and $\$ 207$ million in direct costs of initial treatment). In the same vein, the decline in opioid

Table 2. Associations between prescription opioid use and untreated caries, edentulism and periodontitis (NHANES 2009, 2011, 2013 and 2015 cycles; $\mathrm{N} \geq 8851$ )

\begin{tabular}{|c|c|c|c|}
\hline Oral health outcome & OR $(95 \% \mathrm{CI})$ & $\begin{array}{l}\text { Six-year risk difference } \\
(95 \% \mathrm{CI})^{\mathrm{a}}\end{array}$ & $\begin{array}{l}\text { One-year risk difference } \\
(95 \% \mathrm{CI})^{\mathrm{b}}\end{array}$ \\
\hline Untreated caries & $1.40(1.04-1.90)^{*}$ & $0.084(0.010-0.159)^{*}$ & $0.015(0.002-0.028)^{*}$ \\
\hline Edentulism (partial or complete) & $1.81(1.32-2.48)^{*}$ & $0.147(0.070-0.223)^{*}$ & $0.026(0.012-0.041)^{*}$ \\
\hline Periodontitis & $1.08(0.75-1.56)$ & $\mathrm{N} / \mathrm{A}$ & $\mathrm{N} / \mathrm{A}$ \\
\hline
\end{tabular}

${ }^{*} \mathrm{p}<0.05$. CI: confidence interval. N/A: not assessed (as the associated odds ratio was not statistically significant). Control covariates in all regression models included gender, age, race/ethnicity, educational level, poverty level, health insurance status, country of birth, number of chronic health conditions, veteran status, depressive symptoms, cigarette smoking, alcohol use, marijuana use, methamphetamine use, cocaine use and heroin use, and NHANES cycle. Untreated caries and edentulism were examined using data from individuals aged $\geq 20$ years that participated in NHANES cycles 2011-2012, 2013-2014, and 2015-2016 (N=11515). Periodontitis was examined using data from individuals aged $\geq 30$ years that participated in NHANES cycles 2009-2010, 2011-2012, and 2013-2014 cycles (N=8851) 
Table 3. Estimated cases and costs of common dental diseases averted by the decline in annual opioid prescriptions

\begin{tabular}{l|c|c|c|c|c|c} 
Analyses & Averted cases $^{f}$ & \multicolumn{2}{|c|}{ Productivity losses averted } & \multicolumn{2}{c|}{ Direct treatment costs averted } & $\begin{array}{c}\text { Total cost } \\
\text { savings }\end{array}$ \\
\cline { 3 - 6 } & & Per capita & Total & Per capita & Total & \$1 \\
Untreated caries & 1164734 & $\$ 77$ & $\$ 105$ million & $\$ 151$ & $\$ 207$ million & $\$ 312$ million \\
Edentulism & 1863574 & $\$ 241$ & $\$ 570$ million & $\$ 225$ & $\$ 532$ million & $\$ 1,102$ million
\end{tabular}

All costs are in 2020 US\$. Total cost savings for averted untreated caries and edentulism cases over the study period are US $\$ 1.42$ billion. $f$ The data were obtained from the Centers for Disease Control and Prevention (U.S. Opioid Dispensing Rate Maps).

prescriptions over the study period may have also prevented over 2.3 million cases of edentulism. With estimated per capita productivity loss and direct treatment costs of $\$ 241$ and $\$ 225$, respectively, averted cases of edentulism resulted in over $\$ 1.1$ billion in cost-savings (i.e. about $\$ 570$ million in productivity loss and $\$ 532$ million in direct costs of initial treatment). Hence, total cost savings from averted cases of untreated caries and edentulism due to the decline in opioid prescriptions between 2013 and 2019 are over \$1.4 billion. Results were robust to alternative assumptions around distributions of use of dental implants and bridges for initial treatment of edentulism.

\section{DISCUSSION}

The evidence presented here suggests that the decline in opioid prescriptions between 2013 and 2019 may have averted over 3.6 million combined cases of untreated caries and edentulism, and may have saved the US economy over $\$ 1.4$ billion. The cost-savings represent $<1 \%$ of the total expenditure of oral/dental healthcare in the US and are conservative (e.g. rates and direct costs of initial treatment of edentulism may be higher than assumed and cost savings do not account for medium-term to long-term costs [e.g. from follow-on treatment]) ${ }^{43}$. Nevertheless, we expect our findings to inform conversations about the economic impact of the opioid crises and to guide future studies exploring the costeffectiveness of current/novel strategies for reducing opioid prescriptions $^{44,45}$.

\section{Limitations}

This study has several limitations. Associations between recent use of prescription opioid and untreated caries/ edentulism are most likely confounded by opioid misuse: 1 in 3 individuals receiving prescription opioids misuse them ${ }^{46}$; and opioid misuse cases often experience oral comorbidities from prolonged periods of intoxication and/ or opioid-seeking habits that typically occur at the expense of oral hygiene/dental care ${ }^{47}$. While opioid misuse may confound these associations, it strengthens study findings by providing insight into additional benefits of prescribing fewer opioids (i.e. averting cases of opioid misuse [about 26 million individuals], opioid use disorder [about 8 million individuals], opioid overdose [possible deaths] and neonatal abstinence syndrome ${ }^{47}$. We encourage future studies exploring cost-savings from averting these additional health conditions/events (including the economic value of averting loss of potential years of life and quality-adjusted life years). Other limitations include risks of reverse causation (e.g. opioid prescriptions following wisdom tooth extraction) and misclassification errors (e.g. social desirability bias while self-reporting substance use behaviors), which may lead to biased estimates or Type 2 error. However, available anecdotal evidence suggests that indicated risks are minimal. The estimated 91 million individuals from whom prescription opioids may have been withheld may be an overestimate (from double counting) as some may have received one or more opioid prescriptions within or across several years. Additionally, we viewed untreated caries and edentulism as mutually exclusive oral health conditions; however, available evidence suggests that these conditions are at opposite ends of the same spectrum, and that both conditions could have occurred in the same individual ${ }^{48}$. Severe scarcity of data precluded estimation of uncertainty measures and motivated a recourse to the grey literature for some input data (e.g. costs of initial treatment of edentilism) ${ }^{29-42}$. Lastly, study findings may not extend to populations excluded from NHANES (e.g. persons incarcerated, those in nursing homes and other institutions, and active-duty military personnel).

\section{CONCLUSIONS}

The decline in dispensed prescription opioids between 2013 and 2019 may have averted over 3.6 million combined cases of untreated dental caries and edentulism while saving the US economy over $\$ 1.4$ billion.

\section{REFERENCES}

1. Health Quality Ontario. Patient Safety Learning Systems: A Systematic Review and Qualitative Synthesis. Ont Health Technol Assess Ser. 2017;17(3):1-23. Accessed May 9, 2021. https://www.hqontario.ca/Portals/0/documents/evidence/ reports/hta-patient-safety-1703-en.pdf

2. Economic Toll of Opioid Crisis in U.S. Exceeded $\$ 1$ Trillion Since 2001. Altarum. February 13, 2018. Accessed May 9, 2021. https://altarum.org/news/economic-toll-opioid-crisisus-exceeded-1-trillion-2001\#: :text=Washington $\% 2 C \% 20$ 
DC $\% 20 \%$ E2\%80\%94\%20The $\% 20$ cost $\% 20$ of,health $\% 20$ research $\% 20$ and $\% 20$ consulting\%20institute

3. Kirson NY, Shei A, White AG, et al. Societal economic benefits associated with an extended-release opioid with abuse-deterrent technology in the United States. Pain Med. 2014;15(9):1450-1454. doi:10.1111/pme.12489

4. Chazin S. Getting to the Root of the Problem: Reducing Overuse of Opioids for Oral Pain. Center for Health Care Strategies. March 28, 2018. Accessed May 13, 2019. https:// www.chcs.org/getting-root-problem-reducing-overuseopioids-oral-pain/

5. Kuehn B. Declining Opioid Prescriptions. JAMA. 2019;321(8):736. doi:10.1001/jama.2019.0647

6. Carlson RG, Nahhas RW, Martins SS, Daniulaityte R. Predictors of transition to heroin use among initially nonopioid dependent illicit pharmaceutical opioid users: A natural history study. Drug Alcohol Depend. 2016;160:127134. doi:10.1016/j.drugalcdep.2015.12.026

7. Finnegan J. Decline in opioid prescriptions translates to drop in drug overdose deaths for the first time in decades. Fierce Healthcare. July 18, 2019. Accessed September 3, 2019. https://www.fiercehealthcare.com/practices/declineopioid-prescriptions-translates-to-drop-drug-overdosedeaths-for-first-time

8. Rozier RG, White BA, Slade GD. Trends in Oral Diseases in the U.S. Population. J Dent Educ. 2017;81(8):eS97-eS109. doi:10.21815/JDE.017.016

9. Shekarchizadeh H, Khami MR, Mohebbi SZ, Ekhtiari H, Virtanen JI. Oral health status and its determinants among opiate dependents: a cross-sectional study. BMC Oral Health. 2019;19(1):5. doi:10.1186/s12903-018-0691-3

10. About the National Health and Nutrition Examination Survey. Centers for Disease Control and Prevention. Updated September 15, 2017. Accessed March 20, 2020. https:// www.cdc.gov/nchs/nhanes/about_nhanes.htm

11. National Health and Nutrition Examination Survey. Centers for Disease Control and Prevention. Updated May 5, 2021. Accessed September 24, 2019. https://www.cdc.gov/nchs/ nhanes/index.htm

12. U.S. Opioid Dispensing Rate Maps. Centers for Disease Control and Prevention. Updated December 7, 2020. Accessed May 13, 2019. https://www.cdc.gov/drugoverdose/maps/rxratemaps.html

13. Eke PI, Page RC, Wei L, Thornton-Evans G, Genco RJ. Update of the case definitions for population-based surveillance of periodontitis. J Periodontol. 2012;83(12):1449-1454. doi:10.1902/jop.2012.110664

14. Fleurence RL, Hollenbeak CS. Rates and probabilities in economic modelling: transformation, translation and appropriate application. Pharmacoeconomics. 2007;25(1):36. doi:10.2165/00019053-200725010-00002

15. Kern DM, Cepeda MS, Salas M, Phillips S, Secrest MH, Wedin GP. Frequency of Early Refills for Opioids in the United States. Pain Med. 2020;21(9):1818-1824. doi:10.1093/pm/pnaa161 16. World Health Organization. Macroeconomics and Health:
Investing in Health for Economic Development. 2001. Accessed May 9, 2021. https://apps.who.int/iris/bitstream/ handle/10665/42435/924154550X.pdf

17. Listl S, Galloway J, Mossey PA, Marcenes W. Global Economic Impact of Dental Diseases. J Dent Res. 2015;94(10):13551361. doi:10.1177/0022034515602879

18. Global Health Estimates 2016: Disease burden by Cause, Age, Sex, by Country and by Region, 2000-2016. World Health Organization; 2018. Accessed February 10, 2020. https:// www.who.int/healthinfo/global_burden_disease/GHE2016_ DALY_Global_2000_2016_xls

19. Eke PI, Thornton-Evans GO, Wei L, Borgnakke WS, Dye BA, Genco RJ. Periodontitis in US Adults: National Health and Nutrition Examination Survey 2009-2014. J Am Dent Assoc. 2018;149(7):576-588.e6. doi:10.1016/j.adaj.2018.04.023

20. Dye BA, Thornton-Evans G, Li X, Iafolla TJ. Dental Caries and Tooth Loss in Adults in the United States, 2011-2012. U.S. Department of Health and Human Services, Centers for Disease Control and Prevention, National Center for Health Statistics; 2015. NCHS data brief, no 197. May 2015. Accessed May 9, 2021. https://www.cdc.gov/nchs/data/ databriefs/db197.pdf

21. Dental Caries (Tooth Decay). National Institute of Dental and Craniofacial Research. Updated July, 2018. Accessed May 15, 2019. https://www.nidcr.nih.gov/research/data-statistics/ dental-caries

22. Dental Caries (Tooth Decay) in Adolescents (Age 12 to 19). National Institute of Dental and Craniofacial Research. Updated July, 2018. Accessed February 20, 2020. https:// www.nidcr.nih.gov/research/data-statistics/dental-caries/ adolescents

23. Dental Caries (Tooth Decay) in Adults (Age 20 to 64). National Institute of Dental and Craniofacial Research. Updated July, 2018. Accessed February 10, 2020. https:// www.nidcr.nih.gov/research/data-statistics/dental-caries/ adults

24. Dental Caries (Tooth Decay) in Seniors (Age 65 and Over). National Institute of Dental and Craniofacial Research. Updated July, 2018. Accessed February 10, 2020. https:// www.nidcr.nih.gov/research/data-statistics/dental-caries/ seniors

25. The American College of Prosthodontists. Talking Points: Missing Teeth. Accessed February 10, 2020. https://www. prosthodontics.org/assets/1/7/ACP_Talking_points_for_ Missing_Teeth_1-12-15.pdf

26. Albert DA, Sadowsky D, Papapanou P, Conicella ML, Ward A. An examination of periodontal treatment and per member per month (PMPM) medical costs in an insured population. BMC Health Serv Res. 2006;6:103. doi:10.1186/1472-6963-6-103

27. O'Connell J, Rockell J, Ouellet J, Tomar SL, Maas W. Costs And Savings Associated With Community Water Fluoridation In The United States. Health Aff (Millwood). 2016;35(12):22242232. doi:10.1377/hlthaff.2016.0881

28. Lee D. How much do dentures cost? Bankrate. February 17, 2017. Accessed May 15, 2019. https://www.bankrate.com/ 
finance/smart-spending/how-much-do-dentures-cost.aspx

29. Frothingham $S$. What is a dental bridge? Healthline Media. Updated June 13, 2018. Accessed May 15, 2019. https:// www.healthline.com/health/dental-bridge

30. Cost of Dental Implants Broken Down. Spirit Dental \& Vision. January 30, 2018. Accessed May 15, 2019. https:// spiritdental.com/blog/categories/procedures/the-cost-ofdental-implants-broken-down

31. Facts and Figures. The American College of Prosthodontists. Accessed May 15, 2019. https://www.gotoapro.org/factsfigures /

32. Dental Implant Cost: What to Expect. Distinctive Dental Care. Updated November 6, 2020. Accessed May 8, 2021. https:// www.wulffdmd.com/blog/dental-implant-cost-what-toexpect/

33. Full Mouth Dental Implants Cost. John T. Green DDS Inc. Accessed May 8, 2021. https://www.johntgreendds.com/ full-mouth-dental-implants-cost/

34. How Much Do Dental Implants Cost? Fixodent. Accessed May 8, 2021. https://www.dentureliving.com/en-us/advicetips/preparing-for-dentures/costs/how-much-do-dentalimplants-cost

35. Average Costs: Dentistry and Orthodontia. CareCredit. Accessed May 8, 2021. https://www.carecredit.com/ dentistry/costs/

36. Bautista DS. Dental Implants Procedure, Types, Problems, and Cost. Updated December 23, 2019. Accessed May 8, 2021. https://www.medicinenet.com/dental_implants/ article.htm

37. Hill A. How to Get Low Cost Dental Implants. NewMouth. Updated January 6, 2021. Accessed May 8, 2021. https:// www.newmouth.com/blog/low-cost-dental-implants/

38. How much does a dental bridge cost? AspenDental. Accessed May 8, 2021. https://www.aspendental.com/pricing-offers/ dental-bridge-cost

39. Dental Bridges: The Cost of Bridging the Gap. Consumer Guide to Dentistry. Accessed May 8, 2021. https://www. yourdentistryguide.com/bridges/

40. How Much Does a Dental Bridge Cost with Insurance. Voss Dental. November 11, 2020. Accessed May 8, 2021. https:// vossdental.com/how-much-does-a-dental-bridge-cost-withinsurance/

41. How Much Do Does A Dental Bridge Cost? Wake Dental Care.

\section{CONFLICTS OF INTEREST}

The authors have completed and submitted the ICMJE Form for Disclosure of Potential Conflicts of Interest and none was reported.

FUNDING

There was no source of funding for this research. The views expressed here are those of the authors and not their institutions.

ETHICAL APPROVAL AND INFORMED CONSENT

Ethical approval and informed consent were not required for this study, as data used were publicly available. As per Common Rule (45 CFR 46), nonhuman research was performed.
Accessed May 8, 2021. https://www.wakedentalcare.com/ dental-bridge-cost/

42. Burhenne M. Do you need a dental bridge? 4 Types, Cost, Uses \& Alternatives. Ask The Dentist. Updated February 26, 2020. Accessed May 8, 2021. https://askthedentist.com/ dental-bridges/

43. American Dental Association. U.S. dental expenditures: 2017 Update. Health Policy Institute, American Dental Association; 2017. Accessed May 9, 2021. https://www.ada.org/ / media/ADA/Science\%20and\%20Research/HPI/Files/ HPIBrief_1217_1.pdf

44. Wilson N, Kariisa M, Seth P, Smith H, Davis NL. Drug and Opioid-Involved Overdose Deaths - United States, 20172018. MMWR Morb Mortal Wkly Rep. 2020;69(11):290-297. doi:10.15585/mmwr.mm6911a4

45. Zhu W, Chernew ME, Sherry TB, Maestas N. Initial Opioid Prescriptions among U.S. Commercially Insured Patients, 2012-2017. N Engl J Med. 2019;380(11):1043-1052. doi:10.1056/NEJMsa1807069

46. Vowles KE, McEntee ML, Julnes PS, Frohe T, Ney JP, van der Goes DN. Rates of opioid misuse, abuse, and addiction in chronic pain: a systematic review and data synthesis. Pain. 2015;156(4):569576. doi:10.1097/01.j.pain.0000460357.01998.f1

47. Wagner CL, Holmgren J, Sunstrum B, Tu H, Nadeau R. Associations with a Postoperative Opioid Prescription Following Third Molar Surgery. J Oral Maxillofac Surg. 2019;77(9)(suppl):e43. doi:10.1016/j.joms.2019.06.160

48. Slade GD, Akinkugbe AA, Sanders AE. Projections of U.S. Edentulism Prevalence Following 5 Decades of Decline. J Dent Res. 2014;93(10):959-965. doi:10.1177/0022034514546165

DATA AVAILABILITY AND SHARING

Data sharing is not applicable to this article as no new data was created.

AUTHORS' CONTRIBUTIONS

All authors contributed to study conceptualization, study design, statistical analyses, and manuscript preparation. All authors approve the final manuscript as submitted and agree to be accountable for it.

PROVENANCE AND PEER REVIEW

Not commissioned; externally peer reviewed. 